\title{
Pharmacokinetic Study of Hibiscus Rosa-sinenses-L
}

\author{
Bhawna Pandey ${ }^{1}$, Arvind Prasad Dwive di ${ }^{2}$, S. K. Nigam ${ }^{3}$, S. S. Paihar ${ }^{1}$ \\ ${ }^{1}$ Department of Chemistry, Govt. Girls P. G. College, Rewa-486001 (M.P.) India \\ ${ }^{2}$ Department of Chemistry, Sanjay Gandhi Smrati Govt. Auto. P.G. College Sidhi M.P -486661 \\ ${ }^{3}$ Govt. College Rampur Naikin, District Sidhi -486661(M.P.) India
}

\author{
*Corresponding Author: Bhawna Pandey, Department of Chemistry, Govt. Girls P. G. College, Rewa- \\ 486001 (M.P.) India
}

\begin{abstract}
The pharmacokinetic study of medicinal plants Hibiscus Rosa-sinenses-L(HRS) ofmalvaceaefamily in vitro condition have been carried out electrochemically using Ag-Zn pair of electrodes in vitro condition in three different seasons. The investigation shows first to zero order kinetics for complex oscillatory reactions occurring in the system at long span oftime. The reaction velocity enhanced by charge transfer of Zwitterions between biomass and electrodes. The measured activation parameters fully explained the suggested mechanism and activity.
\end{abstract}

Keywords: Bio-electrode potential, respiration, couple, contribution, Zwitter ions.

\section{INTRODUCTION}

The ancient Indian documents, the Vedas emphasize the planting of tree for worshiping material as prosperity, fulfilment of desires and salvation ensure himself against all diseases for seven birth to came. The red hibiscus is the flower of the Hindu goddess Kali in Bengal India and offered goddess and Lord Ganesha in Hindu worship. In light of our Epics, plants purify the atmosphere. They are also source ${ }^{[1]}$ of energy and provide sufficient natural products in the field of drugs and even the medicines to get relief from the disease. The systematic analysis of drugs used in indigenous medicine was taken up on modern scientific lives.

The medicinal plants have important role in the production of medicines and can't be overlooked because of their competitive rate e.g. cortisone and other hormones which are useful for curing diseases. Vigorous researches/ analysis have therefore to be carried out on plant sources which can be used as a anti-cancer. The drugs derived from plant materials will play a significant role in solving the socioeconomic problem of the country.

Now-a-days, a recent survey of CSIR has revealed that the presence of about five thousand efficacious drugs of which about six hundred are newly discovered. The studies of chemical analysis ${ }^{[2]}$ and pharmacokinetic ${ }^{[3-5]}$ of plant products is a fascinating and exciting subject in the modern age. With the advancement of chemistry of natural products/ phytochemistry enormous uses of plants began to be recognized.

It is postulated that HRS interacts with diclofenace, chloroquine and acetaminophen by altering the pharmacokinetics ${ }^{[6]}$. In healthy human volunteers, an additionally Co-administration of HRS was found to reduce chloroquine bioavailability. However no statistically significant changes were observed in the pharmacokinetic of acetaminophen when administered with HRS.

The review of the literature reveals that kinetic study of medicinal plants and their drugs have been earlier reported by a couple of workers ${ }^{[7-11]}$, but no report on pharmacokinetic study of HRS medicinal plants is available hence we have considered it worthwhile to probe the above task in context of pharmacokinetic study.

\section{EXPERIMENTAL}

All reagents and solvents used in this investigation were of standard grade. The three varieties of Hibiscus Rosa-sinenses-L. abbreviated as $\mathrm{HRS}_{1}, \mathrm{HRS}_{2}$ and $\mathrm{HRS}_{3}$ selected for the pharmacokinetic analysis. Hibiscus is a genus of flowering plants in malvaceae family with hundred species that are 
native to warm grown in subtropical and tropical regions throughout India. It includes both woody shrubs and small trees. The leaves are alternate ovate and often with toothed. The flowers are large and of red and white colours.

All the measurements have been made through digital panel meter. The study was initiated by dipping Ag-Zn pair of electrodes in biomass (electrolyte) of the system and measuring their bio-electrode potential (BEP) in three different seasons viz. Summer(S), Rainy (R), and Winter (W) respectively. The rate constant was determined by integration method $[\mathrm{k}=2.303 / \mathrm{t} \log \mathrm{a} /(\mathrm{a}-\mathrm{x})]$ at different intervals of time. The activation parameters for the systems under investigation were also evaluated.

\section{ReSULTS AND Discussion}

The observed data of the pharmacokinetic studies of chemical constituents of medicinal plants $\mathrm{HRS}_{1}$, $\mathrm{HRS}_{2}$ and $\mathrm{HRS}_{3}$ in vitro condition was obtained and values of $\log \mathrm{a} /(\mathrm{a}-\mathrm{x})$ or $\log (\mathrm{a}-\mathrm{x})$ were plotted against the time, a straight line with almost unit slope was found (Fig.1), showing first-order kinetics.

It is obvious from the exemplary of $\mathrm{HRS}_{1}$ the bio-electrode potential (BEP) gradually decreases in long span of time (Table 1). The kinetics becomes very complicated due to occurrence of frequently oscillatory reactions with stiff vibrations, where order falls from 1 to zero for the systems. A similar observation was found with $\mathrm{HRS}_{2}$ and $\mathrm{HRS}_{3}$ in different seasons of the systems. The added solution of catalyst $\left[\mathrm{CuSO}_{4}\right]=1.0 \times 10^{-3}\left(\mathrm{~mol} \mathrm{dm}^{-3}\right)$ reduces the BEP as well as the rate: $\mathrm{k}_{\text {obs }}$ are $12.58 \times 10^{-6} \mathrm{~s}^{-1}$ (W), $12.05 \times 10^{-6} \mathrm{~s}^{-1}(\mathrm{~S})$, and $12.17 \times 10^{-6} \mathrm{~s}^{-1}(\mathrm{R})$ for $\mathrm{HRS}_{1}$ respectively. It was observed that rate of reaction almost remains unchanged by the addition of $\mathrm{C}_{6} \mathrm{H}_{12} \mathrm{O}_{6}$ solution to the electrolyte of the systems, and play no role of respiration in operational mechanism of BEP. The neutral salts like $\mathrm{NaCl}$ and $\mathrm{KCl}$ each of concentration $1.00 \times 10^{-3}$ to $2.50 \times 10^{-3}\left(\mathrm{~mol} \mathrm{dm}^{-3}\right)$ causes increase in rate due to supplemented of an additional ionic contribution to BEP of the charge transfer reaction. The study reveals that stronger the charge on the ion, the less probable is the ions entry in to a cell. ${ }^{[12]}$

The number of tissues present in biomass is directly proportional to the BEP that obey redox process. The photo excitation activate the mesophycell of the leaf in the morning consequently transition of electrons take place to higher energy, Fermi level $\varepsilon$ (interface of anode) as a result of which the rate is highest during photosynthesis. An electrical double layer of oppositely charged ions are formed between electrolyte and Ag-Zn pair of electrodes which is responsible for development of BEP. Moreover Zwitter ions of amino acids get decomposed equally into anions and cations carrying the current in fuel cell formed. The chlorophyll (block of proteins) and chloroplast across the membrane control the migration of protons within the amino acid.

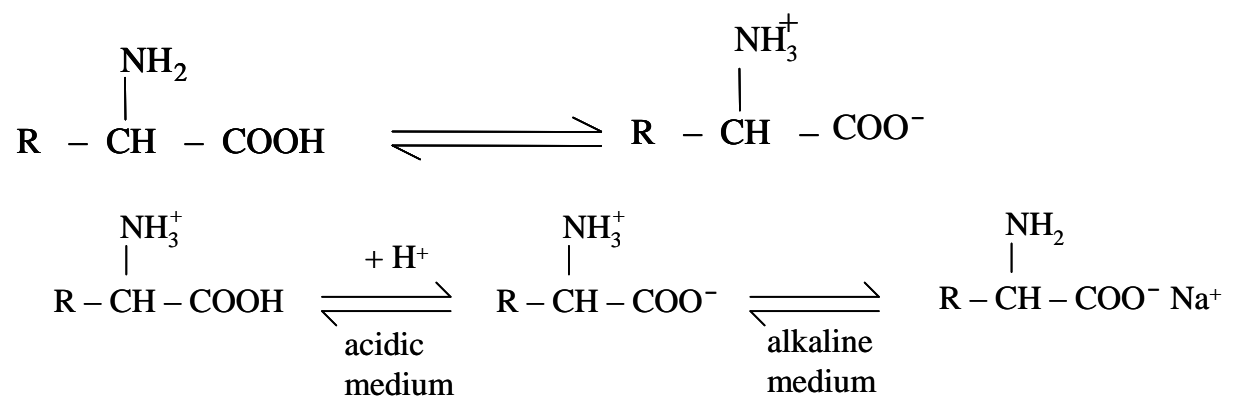

Cation

Zwitter ion

Anion

(Migrates towards cathode)

(Migrates towards anode)

Here equilibria (1, and 2) has been used in elucidation of reaction scheme in the present investigation. Considering the equal decomposition of Zwitter ions of biomass, and other pharmacokinetic results the, brief scheme of mechanism for the title reaction is suggested.

$\mathrm{AA} \stackrel{\mathrm{K}}{\rightleftharpoons}$ Dipolar Zwitter ion

Zwitter ion $\stackrel{\mathrm{k}_{1}}{\longrightarrow}$ Cation
Zwitter ion $\stackrel{\mathrm{k}_{2}}{\longrightarrow}$ Anion 
Using the concept of formation of electrical double layers between electrolyte and electrodes, the rate expression may be derived as:

The rate of decomposition of complex $=\mathrm{k}_{1}$ [cation] $+\mathrm{k}_{2}$ [Anion]

From equations (1) and (5), the final rate is deduced as:

$$
\begin{aligned}
\frac{\mathrm{dx}}{\mathrm{dt}} & =\mathrm{K} \mathrm{k}_{1} \text { [Amino acid] }+\mathrm{K} \mathrm{k}_{2} \text { [Amino acid] } \\
\mathrm{k}_{\mathrm{obs}} & =\mathrm{K}\left(\mathrm{k}_{1}+\mathrm{k}_{2}\right)[\mathrm{AA}]
\end{aligned}
$$

The rate law also fully explains all the experimental pharmacokinetic results. Similar mechanism of rate has also been earlier reported by authors ${ }^{[13-15]}$. The observed activity was found in terms of rate for the HRS medicinal plants in different seasons in the following order:

$$
\mathrm{HRS}_{3}(\mathrm{~W})>\mathrm{HRS}_{1}(\mathrm{~S})>\mathrm{HRS}_{2}(\mathrm{R})
$$

The more active plant is expected to have lower Energy of activation (Ea) value and vice versa. The plants give high rate as the $\mathrm{Ea}$ is lowest. The pharmacokinetic study reveals the same mechanism operative which was supported by iso-kinetic behaviour (plot of $\Delta \mathrm{H}^{\#}$ vs. $-\Delta \mathrm{S}^{\#}$, Fig. 2) and the constancy in values of free energy of activation $\left(\Delta \mathrm{G}^{\#}\right)\left(101.31\right.$ to $\left.106.63 \mathrm{~kJ} \mathrm{~mol}^{-1}\right)$ Table-2. The iso-kinetic temperature $\beta=318 \mathrm{~K}$ is well above the experimental temperature.

Likewise the study shows a chemical intermediate coupling electrons flow to ATP production. The definite amount of free energy $\left(\Delta \mathrm{G}^{\#}\right)$ involved in concentration of protons $\left(\mathrm{H}^{+}\right)$on two side of chloroplast membrane during photosynthesis. The resultant electrical potential arises across the membrane is fully responsible for increase in rate. Ag- $\mathrm{Zn}$ pair of electrodes give maximum potential, the reason being that $\mathrm{Ag}$ is larger in size, its outer electron is loosely attached so can easily be detached in comparison to $\mathrm{Zn}$, which possesses high ionization potential due to its complete $\mathrm{d}$ sub-shell. As the living systems are far from thermodynamic equilibrium this difference may be maintained by the cell activities, but suddenly when killed or de-activated, it tries to achieve the thermodynamic equilibrium. [16]

The unequal distribution of ions or potential difference are affected by ionic concentration gradient, ionic sodium ${ }^{[17]}$ chloroplast pumps mitrochondria membrane permeability as the living cell controls, regulates and checks the ionic motion due to the anatomicaldifferences and involvement of bio-activity. This may trigger many enzymatic reactions and increasing number of cells. ${ }^{[18]}$ The pharmacokinetic reactions are both enthalpy and entropy controlled.

Table1.Typical pharmacokinetic study

$\begin{array}{lll}\text { System } & : & \text { Hibiscus Rosa-sinenses-L }\left(\mathrm{HRS}_{1}\right) \\ \text { Electrode pair } & : & \mathrm{Ag}-\mathrm{Zn} \\ \text { Season } & : & \text { Winter } \\ \text { Temperature } & : & 291 \mathrm{~K}\end{array}$

\begin{tabular}{|c|c|c|c|c|c|}
\hline S. No. & $\begin{array}{c}\text { Time } \times \mathbf{1 0}^{\mathbf{2}} \\
(\mathbf{S E C})\end{array}$ & $\begin{array}{c}\text { Bio-electrode } \\
\text { potential (BEP) } \\
(\mathbf{m V})\end{array}$ & $\log \frac{\mathbf{a}}{\mathbf{( a - X )}}$ & $\log (\mathbf{a}-\mathbf{x})$ & $\mathbf{k} \times \mathbf{1 0}^{\mathbf{6}}\left(\mathbf{s}^{\mathbf{- 1}}\right)$ \\
\hline 1. & 0 & 1535 & - & 3.18 & - \\
\hline 2. & 144 & 1303 & 0.071 & 3.11 & 11.38 \\
\hline 3. & 288 & 1123 & 0.135 & 3.05 & 10.80 \\
\hline 4. & 432 & 917 & 0.223 & 2.96 & 11.92 \\
\hline 5. & 576 & 749 & 0.311 & 2.87 & 11.24 \\
\hline 6. & 720 & 524 & 0.466 & 2.71 & 14.90 \\
\hline 7. & 864 & 463 & 0.520 & 2.66 & 13.80 \\
\hline 8. & 1008 & 410 & 0.573 & 2.61 & 13.00 \\
\hline
\end{tabular}

BEP: Bio-electrode potential

Average $\mathrm{k}=12.19 \times 10^{-6}\left(\mathrm{~s}^{-1}\right)$

Graphical $\mathrm{k}=12.15 \times 10^{-6}\left(\mathrm{~s}^{-1}\right)$

International Journal of Advanced Research in Chemical Science (IJARCS) 


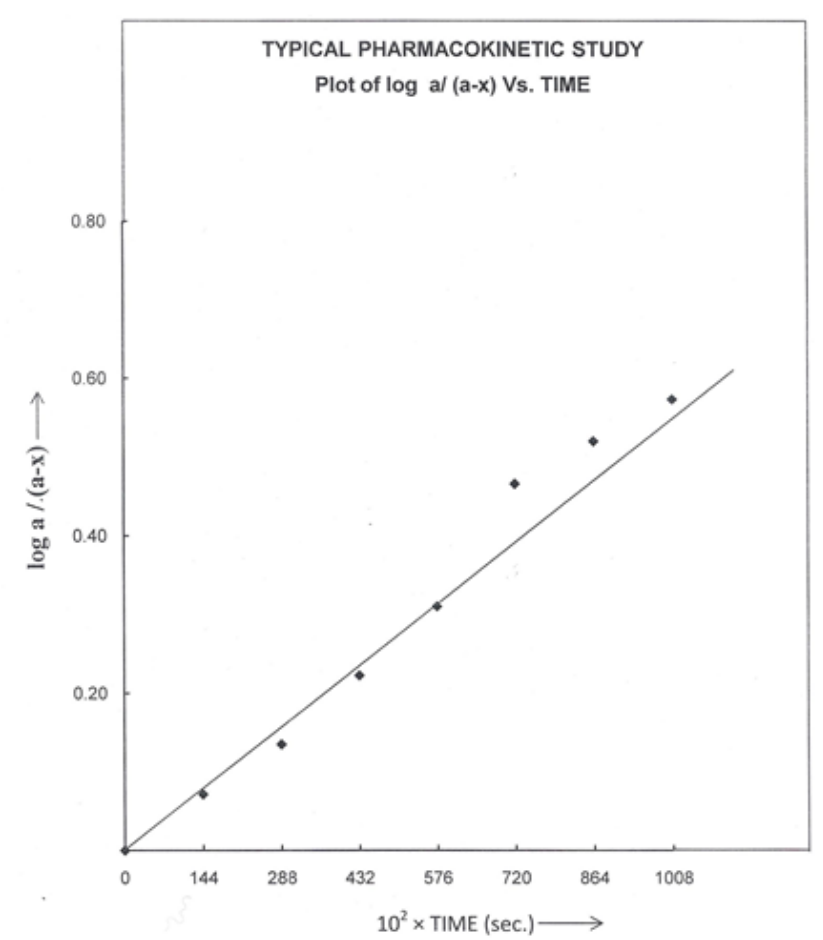

Fig1. System: Hibiscus Rosa-sineses-L (HRS1); Electrode pair: Ag-Zn, Season: Winter(W); Temperature: 291 K Table2. Thermodynamic parameters

\begin{tabular}{|c|c|c|c|c|c|c|c|}
\hline $\begin{array}{c}\text { S. } \\
\text { No. }\end{array}$ & System & Season & $\begin{array}{c}\text { Ea } \\
(\mathbf{k J}) \\
\left(\mathbf{m o l}^{-1}\right)\end{array}$ & $\underset{\left(\mathbf{s}^{-1}\right)}{\mathbf{A}}$ & $\begin{array}{c}\Delta \mathbf{H}^{\#} \\
(\mathbf{k J}) \\
\left(\mathbf{m o l}^{-1}\right)\end{array}$ & $\begin{array}{c}\Delta \mathrm{G}^{\#} \\
(\mathbf{k J}) \\
\left(\mathrm{mol}^{-1}\right)\end{array}$ & $\begin{array}{c}-\Delta \mathbf{S}^{\#} \\
\left(\mathrm{JK}^{-1}\right) \\
\left(\mathrm{mol}^{-1}\right)\end{array}$ \\
\hline 1 & $\mathrm{HRS}_{1}$ & Summer (S) & 4.98 & $9.83 \times 10^{5}$ & 2.62 & 100.74 & 26.12 \\
\hline 2 & $\mathrm{HRS}_{2}$ & Rainy (R) & 6.92 & $2.185 \times 10^{4}$ & 3.94 & 105.64 & 20.66 \\
\hline 3 & $\mathrm{HRS}_{3}$ & Winter $(\mathrm{W})$ & 5.27 & $1.08 \times 10^{4}$ & 3.00 & 101.24 & 24.50 \\
\hline
\end{tabular}

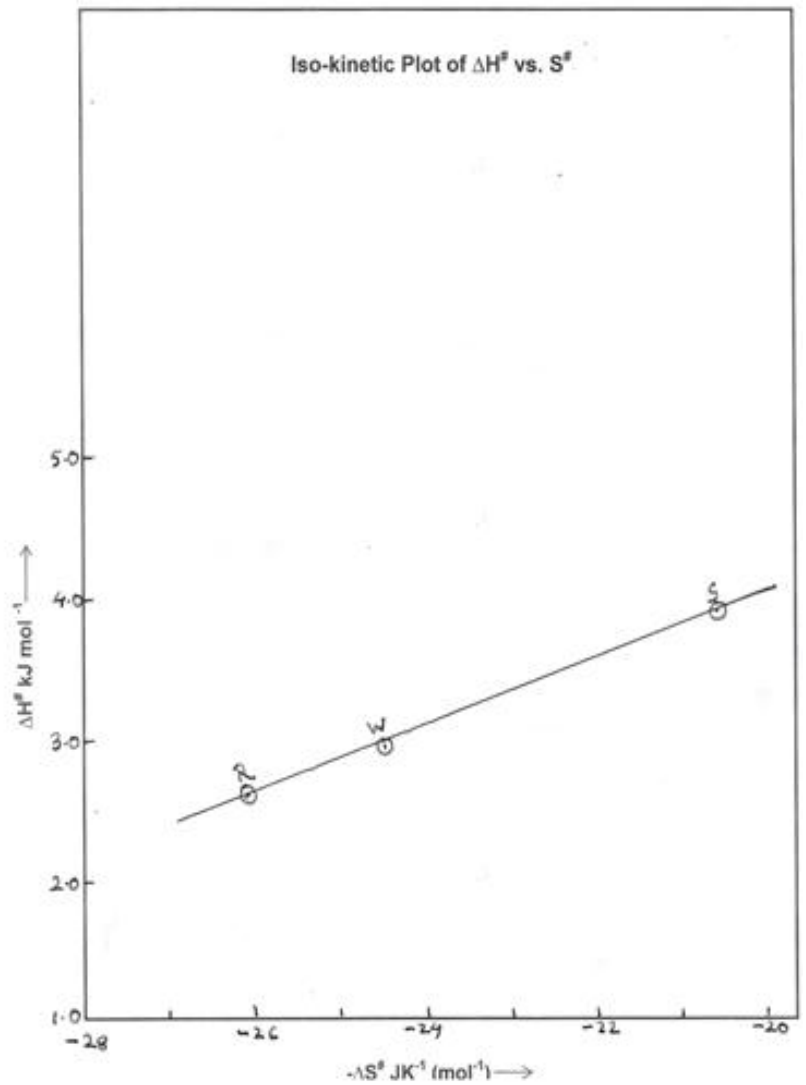

Fig2. System: HRS3; Electrode pair: Ag-Zn; Season: W,S\&R 


\section{CONCLUSiON}

The cell activities of the system maintain thermodynamic equilibrium and responsible for development of bio-electrode potential. The pharmacokinetic study of the system would prove to be very useful in manufacturing of medicines and improving the socio-economic status of farmers growing herbal plants.

\section{REFERENCES}

[1] Boce, J.C., the Nervous Mechanism of Plants, Longmans, Green and Co., London, 1926.

[2] Anupama, P., Ayurveda Herb. 2013, I, 6.

[3] Singh, R.K., Singh, A., Rath, S., and Ramamurthy, A., Int. Ayurvedic Medical Journal 2015, 3(2), 565-569.

[4] Tripathi, K.D., Essentials of Medical Pharmacology VI $^{\text {th }}$ Edn. Jaypee Brothers Medical Publishers (P) Ltd., New Delhi, 2008, 38-44, 101.

[5] Reddi, R., Asian. J. Pharmacodynamics and pharmacokinetics 2010, 6(4), 327-329.

[6] Ali, B.H., Alwabel, N., and Blunden, G., A Review Phytotherapy Res. 2005, 19(5), 369-375.

[7] Zhen, Jing, Thomal, Phytochemistry and Food Chemistry of Hibiscus, 20125, 190, 673-680.

[8] Ojeda, D., J. Ethnopharmocology, 2010, 127, 7-10.

[9] Swami, M.N., and Manikpuri, Nagmani,Elec. J. Advd. Research, 2015, 11, 114-119.

[10] Bunkar, Alka Rani, Int. J. Chem. Studies, 2016, 4(6), 102-104.

[11] Agrawal, R., Khan, M.U., Nigam, S.K., and Khan, Shahnaz, Asian J. Chem., 2007, 19, 213.

[12] Kolawole, J.A., and Maduenyi, A., Eur. J. Drug, Metab. Pharmacokinetic, 2004, 29(i), 25-29.

[13] Harvey, A.L., Drug Discovery Today, 2009, 13, (19-20), 894-901.

[14] Saket, S.S., and Dwivedi, H.P., Proc. 47 ${ }^{\text {th }}$ Annual Convention of Chemists and International conference on Recent Advances in Chemical Science, Raipur, 2010.

[15] Sarabhai, P., Khan, M.U., Nigam, S.K., and Agarwal, R., J. Chem. France, 2007, 2C, No. 06386.

[16] Hiroshi, H., Kazuchiyo, T.M., and Yosshino, Y., Bull. Chem. Soc., Jpn, 1981, 54, 1640.

[17] Beyer, Robbert, E., Energy Transduction in Cells. Intropics in the study of life The Bio source Book Harper and Row, Publishers, Inc. Newyork, 1971, 38-48

[18] Allen, M.J., Electrochemistry, Past and present. John T. Stock and Mary V. Orna, Edns. ACS symposium series No.390, Washington, D.C. 1979

Citation: B. Pandey et al., "Pharmacokinetic Study of Hibiscus Rosa-sinenses-L", International Journal of Advanced Research in Chemical Science (IJARCS), vol. 5, no. 5, pp. 15-19, 2018. http://dx.doi.org/10.20431/ 2349-0403.0505004

Copyright: (c) 2018 Authors. This is an open-access article distributed under the terms of the Creative Commons Attribution License, which permits unrestricted use, distribution, and reproduction in any medium, provided the original author and source are credited. 